\title{
Anatomical variations of knee ligaments in magnetic resonance imaging: pictorial essay
}

\author{
J. Tomczyk' ${ }^{1}$ M. Rachalewski ${ }^{1}$, A. Bianek-Bodzak'1,2,3, M. Domżalski ${ }^{4}$ \\ 'Department of Radiology, Isotopic Diagnostic and Therapy, Military Medical Academy Teaching Hospital, \\ Central Veteran Hospital, Lodz, Poland \\ 2Department of Radiology, Medical University of Gdansk, Poland \\ ${ }^{3}$ Department of Applied Medical Techniques, Medical University of Lodz, Poland \\ ${ }^{4}$ Department of Orthopaedics, Traumatology and Post-traumatic Rehabilitation, Military Medical Academy \\ Teaching Hospital, Central Veteran Hospital, Lodz, Poland
}

[Received: 11 December 2018; Accepted: 15 January 2019]

\begin{abstract}
Evaluation with magnetic resonance imaging (MRI) is currently a gold standard for comprehensive posttraumatic assessment of the knee joint. Increasing availability of MR systems with stronger magnetic fields and new sequences results in higher resolution of images and thus allows imaging smaller and finer anatomical details, including different anatomical variations.

This article focuses on anatomical variations of knee ligaments, which can mimics pathological structures. Well-known and less common ligaments that are sporadically observed and may raise the most doubt will be discussed. Familiarity with those variations of ligaments is indispensable for precise MRI reporting to avoid misinterpretation as meniscal tears, loose bodies or mass lesions especially in cases. This paper is addressed to both radiology and orthopaedics specialists. Illustrations show discussed ligaments in standard planes while, for less known ligaments, we add information on how to adjust planes to properly visualise a particular structure, which will hopefully facilitate finding and differentiating those structures in clinical practice. (Folia Morphol 2019; 78, 3: 467-475)
\end{abstract}

Key words: knee, ligament, anatomical variation, magnetic resonance imaging

\section{INTRODUCTION}

Technological advancement of magnetic resonance imaging (MRI) makes it the most precise method of assessing the knee joint. Availability of more powerful magnets and new sequences allows imaging very small anatomical details.

The knee, as the most weight-bearing joint in the human body, is also the most commonly injured one. Evaluation with MRI is currently a gold standard for comprehensive posttraumatic assessment of the knee joint.
Increasing availability of devices with stronger magnets and new sequences results in higher resolution of images and thus allows imaging smaller and smaller anatomical details, including different anatomical variations.

An anatomical variation is defined as a physiological structure that is not always present, or as a structure present in all cases but in different morphological forms.

Thorough knowledge of possible anatomical variations within the knee is essential to avoid misdiag-

Address for correspondence: J. Tomczyk, MD, Department of Radiology, Isotopic Diagnostic and Therapy, Military Medical Academy Teaching Hospital, Central Veteran Hospital, ul. Żeromskiego 113, 90-549 Łódź, Poland, tel: +48 781339848 , fax: +48 42 639 3402 ,

e-mail: jol.tomczyk@gmail.com 


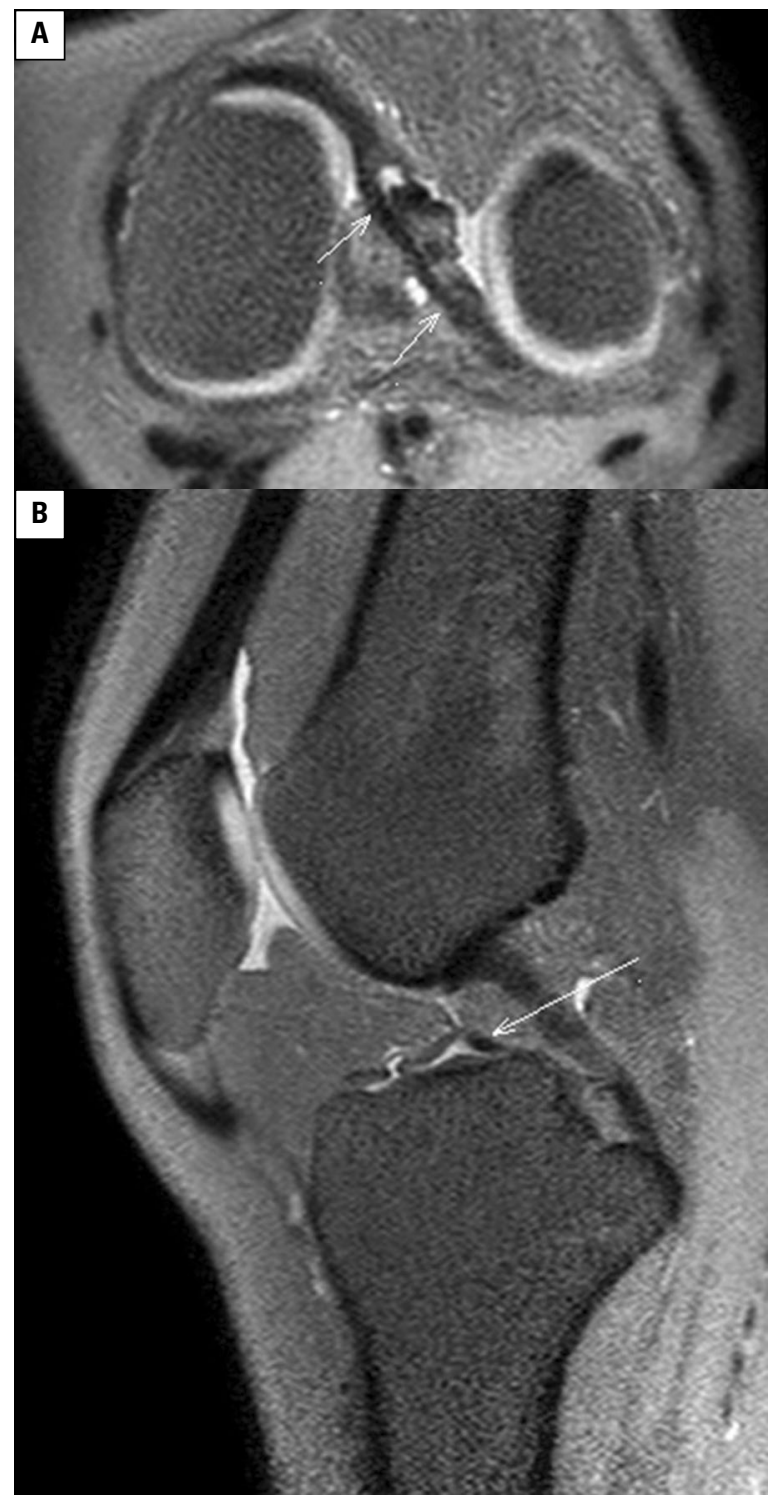

Figure 1. Oblique menisco-meniscal ligament (OMML); A. Cross section in proton-density (PD)-weighted sequence with fat suppression. Arrows indicate the ligament originating from the anterior horn and running to the posterior horn of the opposite meniscus;

B. Sagittal section in PD weighted sequence with fat suppression.

noses. This article reviews both well-known and less common ligamentous anatomical variations within the knee and focuses on those, which can be confused with pathological conditions or may simply cause uncertainty.

\section{OBLIQUE MENISCO-MENISCAL LIGAMENT}

The oblique menisco-meniscal ligament (OMML) (Fig. 1) is a relatively uncommon ligament occurring in $2-4 \%$ of knees $[8,28]$. OMML runs from the an- terior horn of one meniscus to the posterior horn of the other, passing along the tibial plateau between anterior cruciate ligament $(\mathrm{ACL})$ and posterior cruciate ligament $(\mathrm{PCL})$. There are two types of $\mathrm{OMML}-$ medial and lateral — classified depending on the anterior horn of the meniscus from which they originate. On sagittal and coronal images, it can be misinterpreted as either a centrally displaced meniscal tear or collapsed fibres from an ACL tear. In the absence of any other meniscal or cruciate abnormality, it is relatively straightforward to recognise as an anatomical variant, but in the presence of an ACL or meniscal injury it can be confusing. Tracing the well-defined ligament from medial to lateral compartments where it unites smoothly with the two menisci confirms the diagnosis.

\section{ANTERIOR OR TRANSVERSE INTERMENISCAL LIGAMENT}

The anterior (transverse) intermeniscal ligament (Fig. 2) is identified in about $94 \%$ of knees on arthroscopy and is noticeable in about $58 \%$ of knees subjected to MRI $[21,30]$. It runs from the anterior part of the convex edge of the lateral meniscus to the anterior horn of the medial meniscus. The ligament varies in thickness and may be absent in a few per cent of knees. When the thickness of the attachments to the menisci is $3 \mathrm{~mm}$ or more, it is called the "cord-like" variation [27]. A sagittal section through the anterior horn at this position, where the anterior horn is typically reducing in size, can give the impression of a high signal cleft, or pseudo-tear, particularly with the "cord-like" variation [2].

In about $2 \%$ of knees there is also a similar posterior intermeniscal ligament connecting posterior horns of both the menisci [35].

The literature also describes cases of unilateral menisco-meniscal ligaments, which means that they run between the anterior and posterior horns of the same meniscus [6].

\section{MENISCO-FIBULAR LIGAMENT}

In cadaver studies the menisco-fibular ligament (MFL) (Fig. 3) was identified in $100 \%$ of specimens [4].

In studies based on MRI MFL was found in 42-63\% of knees [23]. MFL runs between one-third of the posterior lateral meniscus and the head of the fibula (anteriorly to the tendon of the popliteus muscle). The ligament is often better visible if fluid is present in the posterolateral joint compartment. 


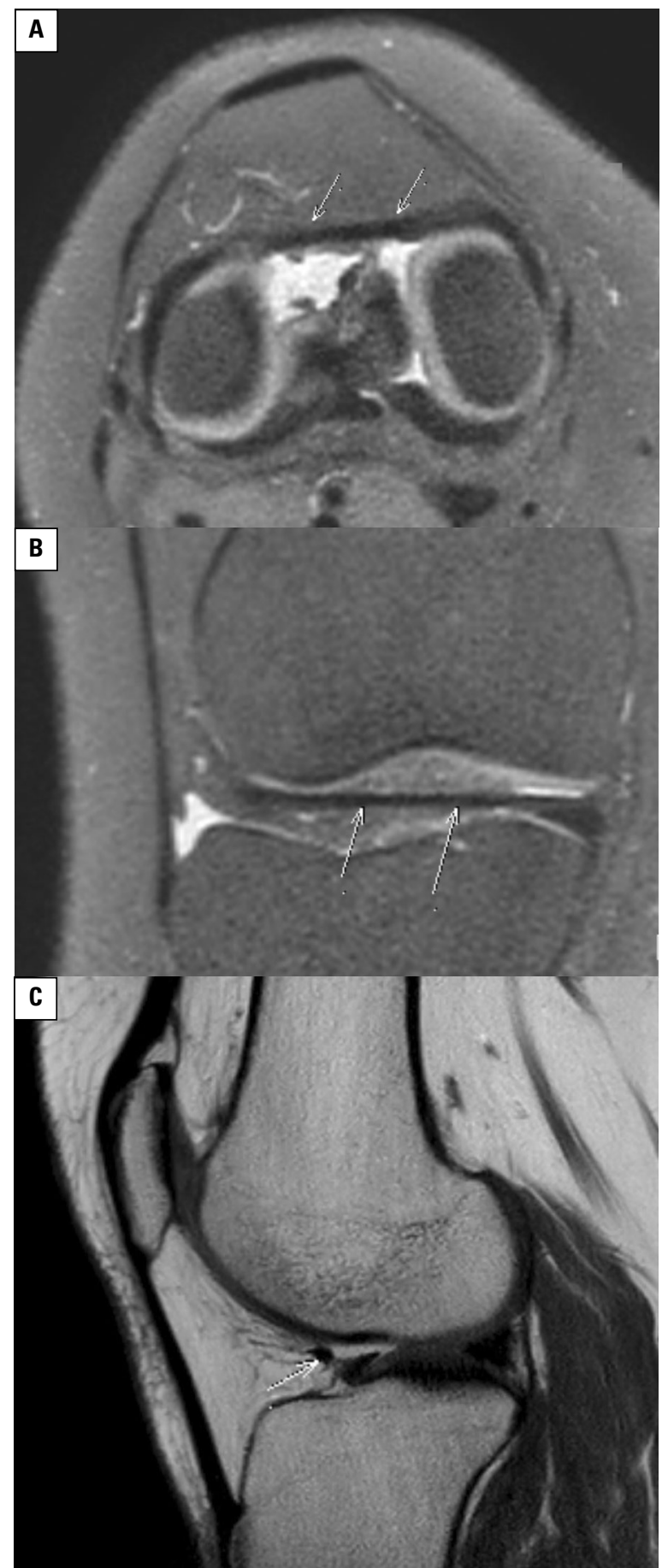

Figure 2. Anterior (transverse) intermeniscal ligament; Cross section (A) and frontal section (B) in proton-density (PD)-weighted sequence with fat saturation. Arrows indicate the ligament originating from the anterior part of the convex edge of the lateral meniscus and running to the anterior horn of the medial meniscus; C. Sagittal section in PD-weighted turbo spin-echo sequence.

Similar to other ligaments with attachments at the meniscus, MFL may mimic meniscal tear. The menisco-fibular ligament is considered to be of key importance in positioning the lateral meniscus.

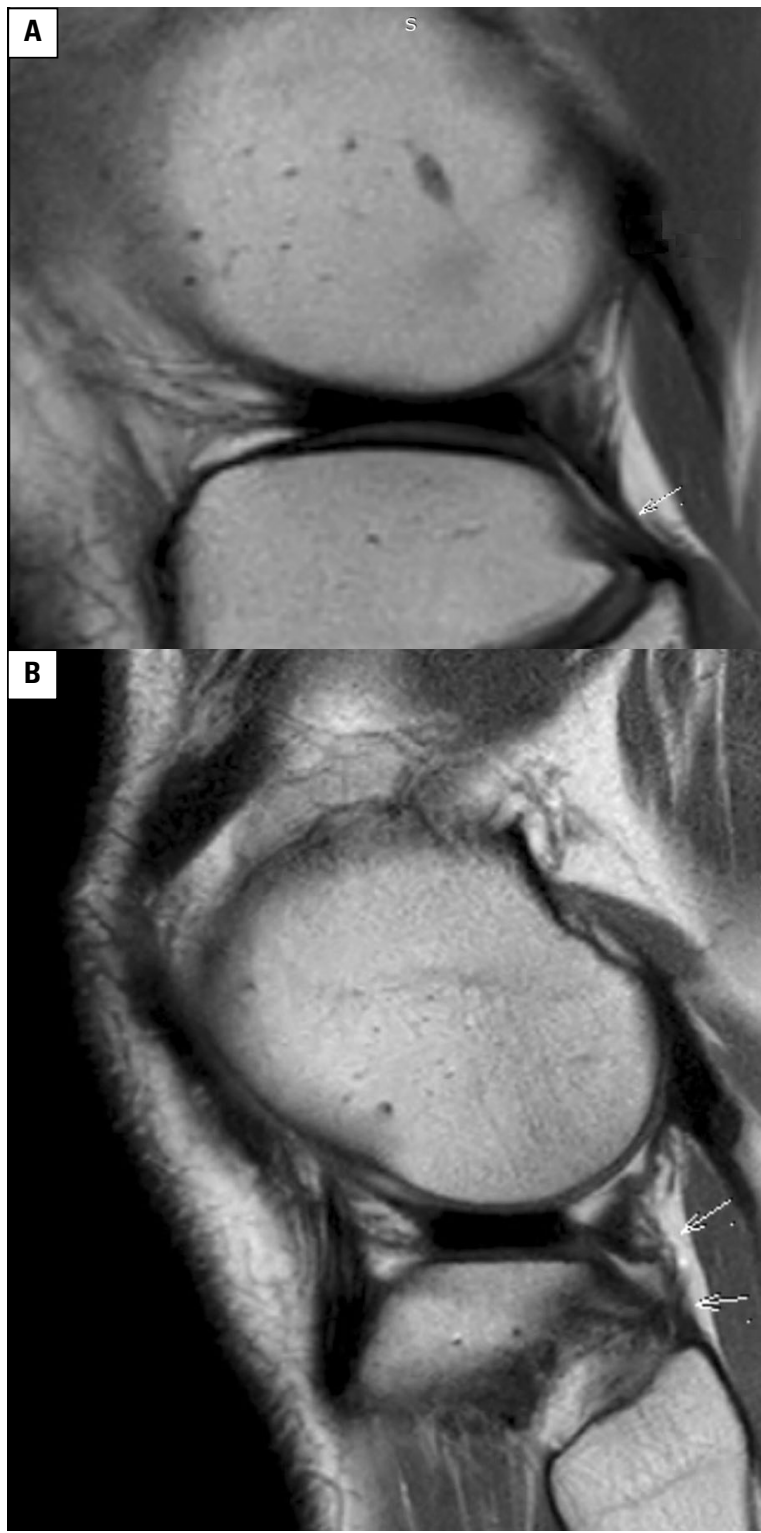

Figure 3. Menisco-fibular ligament; A, B. Sagittal sections in proton-density weighted turbo spin-echo sequence. Arrows indicate the ligament running between one-third of the posterior lateral meniscus and the head of the fibula (anteriorly to the tendon of the popliteus muscle).

\section{MENISCO-FEMORAL LIGAMENT}

The menisco-femoral ligament (MfemL) (Fig. 4) runs from the anterior horn of the lateral meniscus to the lateral part of the medial condyle of the femur or to the posterior cruciate ligament [11].

There are two types of MfemL called, depending on their position in relation to the posterior cruciate ligament $(\mathrm{PCL})$, Humphrey's ligament, running anteriorly to $\mathrm{PCL}$, and Wrisberg's ligament, running posteriorly to PCL [1]. The attachments of those two 


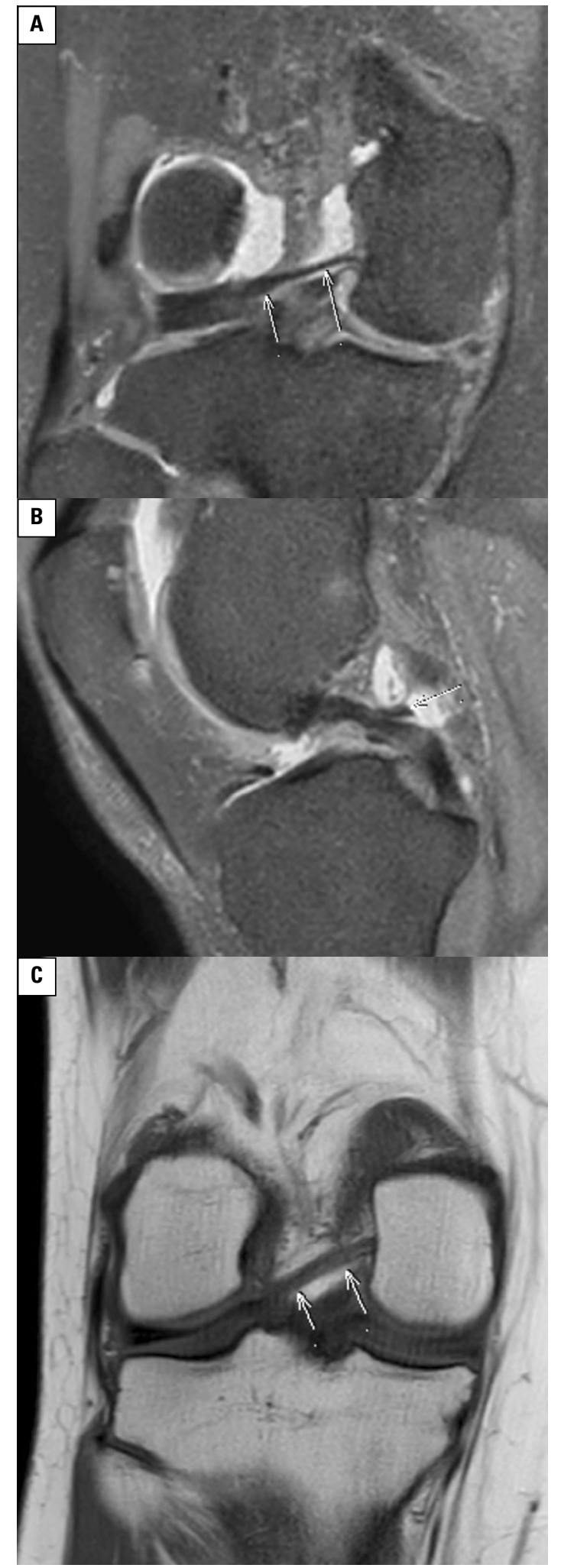

Figure 4. Wrisberg's menisco-femoral ligament (MfemL); A. Frontal plane in proton-density (PD)-weighted turbo spin-echo (TSE) sequence with fat saturation; B. Sagittal plane in PD-weighted TSE sequence. The arrow indicates Wrisberg's ligament running posteriorly to posterior cruciate ligament (black arrowhead) and attached to the medial condyle of the femur (type I); C. Frontal plane in T1-weighted TSE sequence. ligaments are separated, which supports the theory that those are two separate structures and not, as was previously thought, two branches of the same ligament [15].

Depending on the location of the attachment, MfemL is classified into three types:

- type I (46\%) - the medial condyle of the femur;

- type II $(31 \%)$ - the proximal half of the posterior cruciate ligament (PCL);

- type III (21\%) - the distal half of the posterior cruciate ligament (PCL) [7].

In the cadaver study by Gupte at al. of 2002 [11], at least one MfemL was found in $93 \%$ of the studied knee joints. The presence of Humphrey's (anterior menisco-femoral) ligament was established in $74 \%$ specimens while Wrisberg's (posterior menisco-femoral) ligament was found in $69 \%$ of specimens. Both the ligaments were present in $50 \%$ of specimens with the statistically significant prevalence of specimens derived from young individuals. The data may suggest that the absence or presence of only one ligament is associated with degenerative changes or sustained injuries.

Menisco-femoral ligament may mimic PCL damage or lateral meniscus rupture [5, 25].

The literature describes very rare cases of the anteromedial variation of the MfemL running from the anterior horn of the medial meniscus to the posterolateral part of the intercondylar fossa (parallel to the anterior cruciate ligament) [32]. The ligament may mimic the suprapatellar plica.

\section{ARCUATE LIGAMENT}

The arcuate ligament (Fig. 5) is part of the posterolateral ligamentous complex of the knee. It is a $Y$ shaped thickening of the posterolateral part of the joint capsule. It begins at the styloid process of the fibula and divides into two branches: the medial branch running along a curve above the popliteus muscle and attaching to the posterior part of the joint capsule to join the oblique popliteal ligament; the lateral branch running along the lateral part of the joint capsule and attaching to the lateral condyle of the femur.

In the study by Munshi et al. [20] correlating MR arthrography, MRI and cadaver specimen examination, at least one branch of the arcuate ligament was found in $71 \%$ of cases.

The lateral branch was visible in $57 \%$ of specimens (present in $50 \%$ of cases with the fabella and $67 \%$ of 


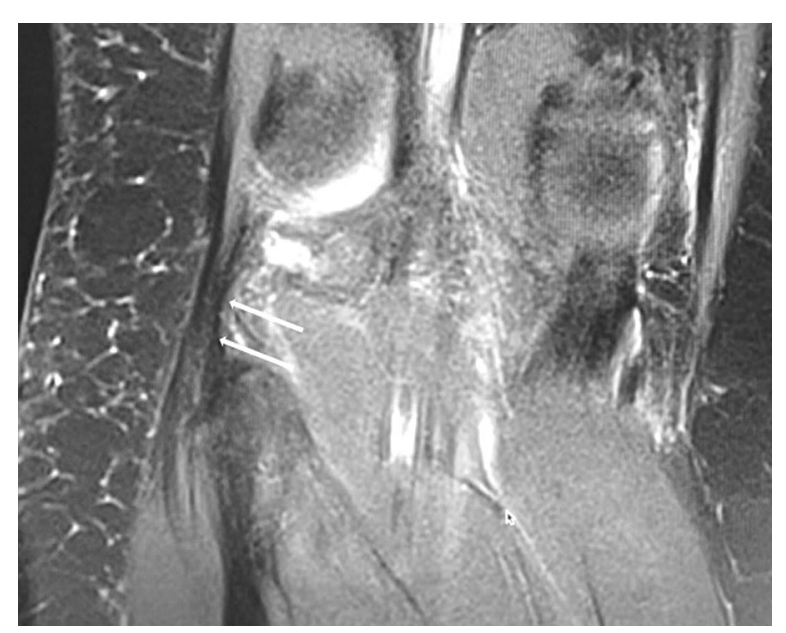

Figure 5. Arcuate ligament in frontal plane in proton-density-weighted turbo spin-echo sequence.

cases without the fabella). The medial branch was visible in $57 \%$ of specimens (present in $75 \%$ of cases with the fabella and $33 \%$ of cases without the fabella).

\section{FABELLO-FIBULAR LIGAMENT}

The fabella is an additional bone typically occurring in the tendon or lateral head of the gastrocnemius muscle of the lower leg. It is present in around $13-20 \%$ of the population $[27,31]$.

The fabello-fibular ligament (FFL) (Fig. 6) runs from the fabella to the styloid process of the fibular head (it attaches laterally related to the popliteo-fibular ligament). It is worth emphasising that the ligament may still be present in the absence of the fabella and attach to the lateral condyle of the femur.

Fabello-fibular ligament was found in $24-80 \%$ of specimens in cadaver studies and in $48 \%$ of examined knees in papers using MR diagnostics [26, 29].

The study by Minowa et al. [19] proved that a bony well-calcified fabella correlates with thicker FFL variations. Moreover, the presence of a thinner FFL variation was statistically significantly correlated with the occurrence of a well-developed arcuate ligament. In turn, the arcuate ligament may be absent in the presence of FFL thicker than $5 \mathrm{~mm}$.

\section{POPLITEO-FIBULAR LIGAMENT}

The popliteo-fibular ligament (PFL) (Fig. 7) is part of the posterolateral ligamentous complex of the knee.

Popliteo-fibular ligament runs from the tendon of the popliteus muscle (proximally to the myotendi-

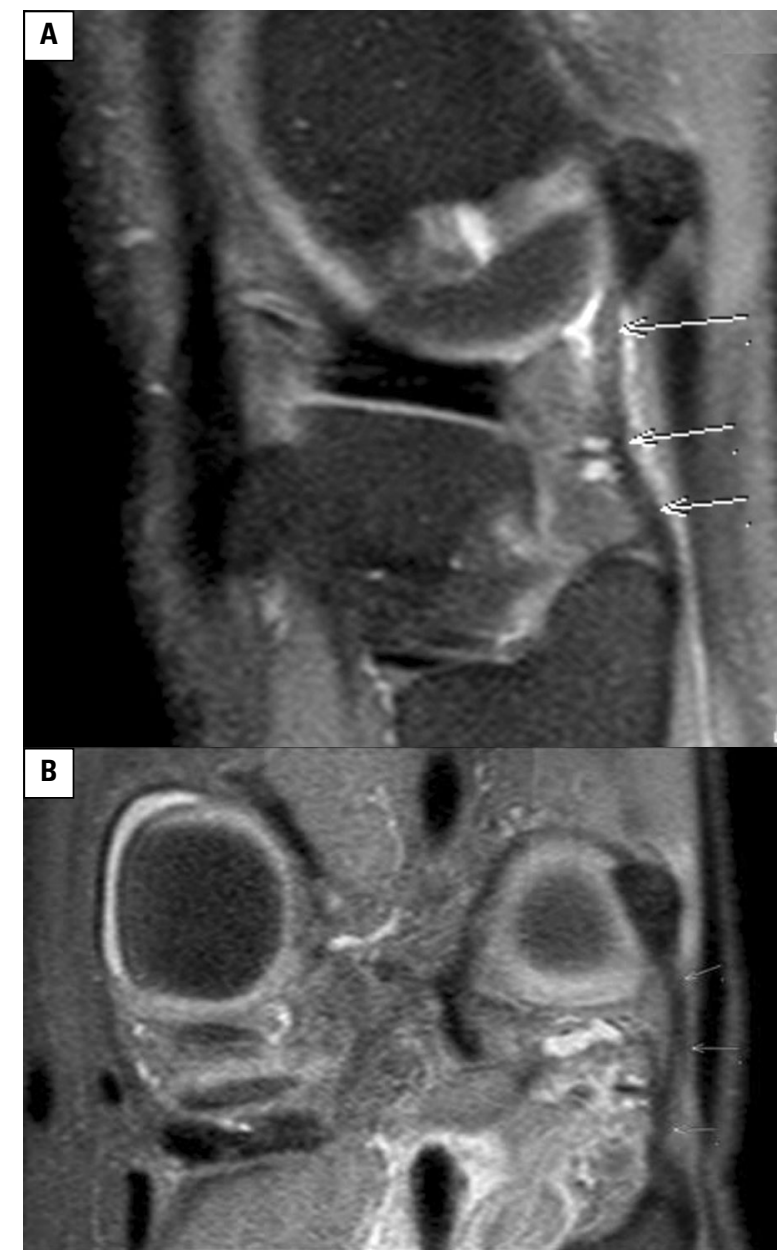

Figure 6. Fabello-fibular ligament; A. In sagittal plane; B. In frontal plane in proton-density-weighted turbo spin-echo sequence with fat saturation. Arrows indicate the ligament running from the fabella to the styloid process of the fibular head.

nous junction) to the fibular head (posteriorly to the attachment of the fibular collateral ligament) [3].

The literature describes two types of PFL:

- type I - with one layer;

- type II - with two layers. Type II is divided into three subtypes:

- Ila - the superficial layer is located anteriorly to the deep layer;

- $\mathrm{llb}$ - the superficial layer and deep layer lie parallel to each other;

- Ilc - the superficial layer is located posteriorly to the deep layer.

In cadaver studies PFL type I was identified in $69.2 \%$ and type II - in $30.8 \%$ of specimens (of which type Ila $9 \%$, Ilb $12.8 \%$, Ilc $9 \%$ ) [12].

In MRI PFL is identified in slightly more than $50 \%$ of examinations and best seen in the frontal and sagittal sections. 


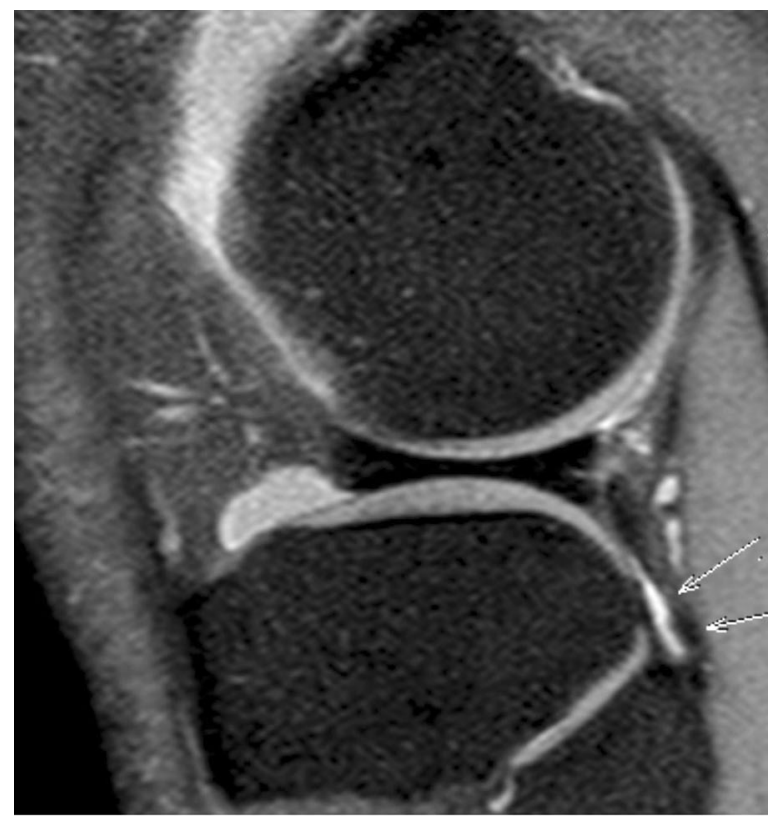

Figure 7. Popliteo-fibular ligament in sagittal plane in proton-density-weighted turbo spin-echo sequence with fat saturation.

\section{ANTERIOR CRUCIATE LIGAMENT}

The anterior cruciate ligament (ACL) (Fig. 8) runs between the posteromedial part of the lateral condyle of the femur and the anterior intercondylar area of the tibia.

There are two bundles of $\mathrm{ACL}$ : the anteromedial bundle is tight in knee flexion and the posterolateral bundle remains tight in knee extension. Both the bundles attach independently to the femur and tibia.

The anterior cruciate ligament is best seen in the sagittal section. The attachments to the femur and tibia are clearly visible in the frontal section although the attachment to the femur is best seen in the cross section.

Anterior cruciate ligament bundles differ in signal intensity in individual sequences. The anteromedial bundle is hypointense in all sequences. In turn, the posterolateral bundle shows intermediate signal intensity in T1-weighted sequences and is moderately hyperintense in proton-density (PD)-weighted, T2-weighted sequences with fat saturation and short TI inversion-recovery (STIR).

There are several deviations from the above-described normal anterior cruciate ligament, which are typically associated with meniscal structure variations. Min et al. [18] reported a case of coalescence between $A C L$ and the lateral part of the discoid medial

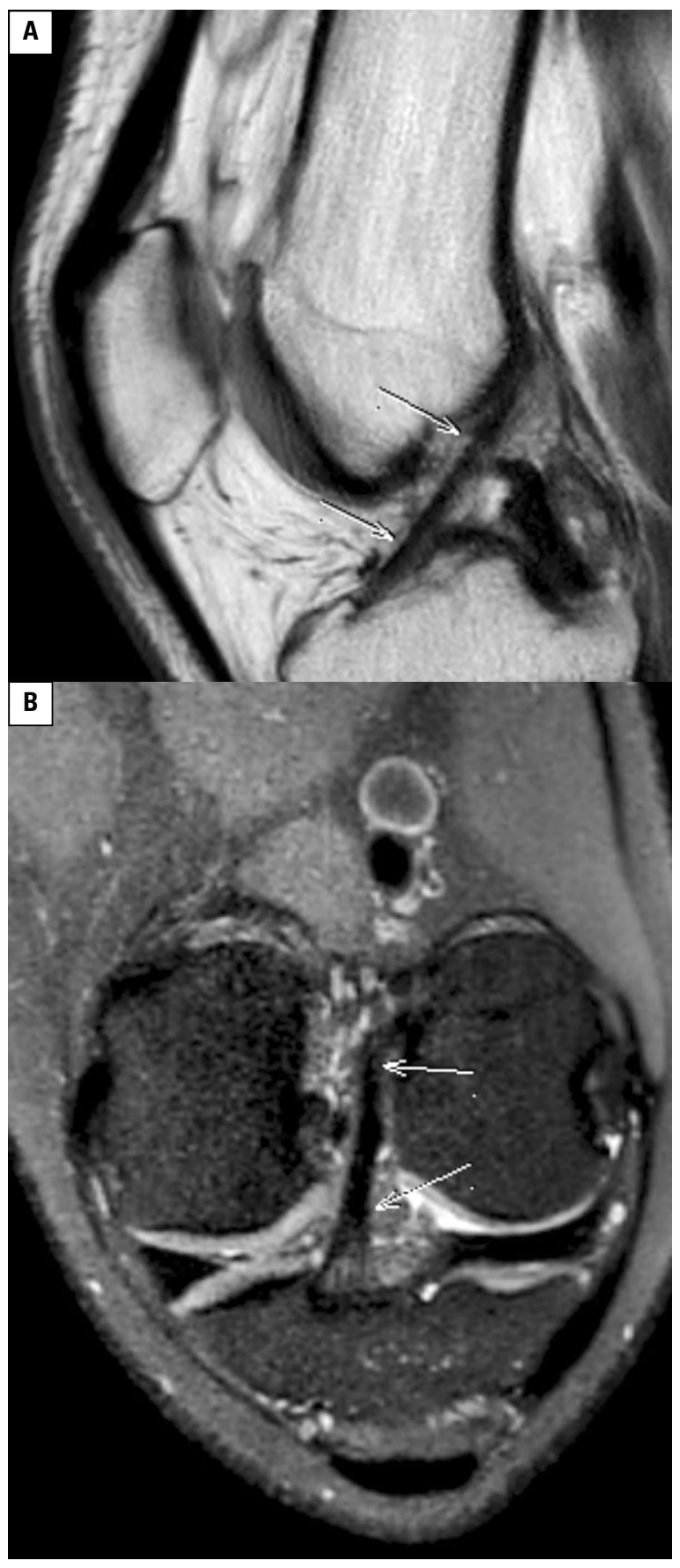

Figure 8. Anterior cruciate ligament; A. In sagittal plane in proton-density (PD)-weighted turbo spin-echo (TSE) sequence; B. In transverse plane n PD-weighted TSE sequence with fat saturation. Arrows indicate the ligament running between the posteromedial part of the lateral condyle of the femur and the anterior intercondylar area of the tibia.

meniscus. The literature also describes a case of $\mathrm{ACL}$ attachment to the anterior horn of the normal medial meniscus - a variation co-occurring in $5.5 \%$ of knees with the discoid lateral meniscus [17]. 


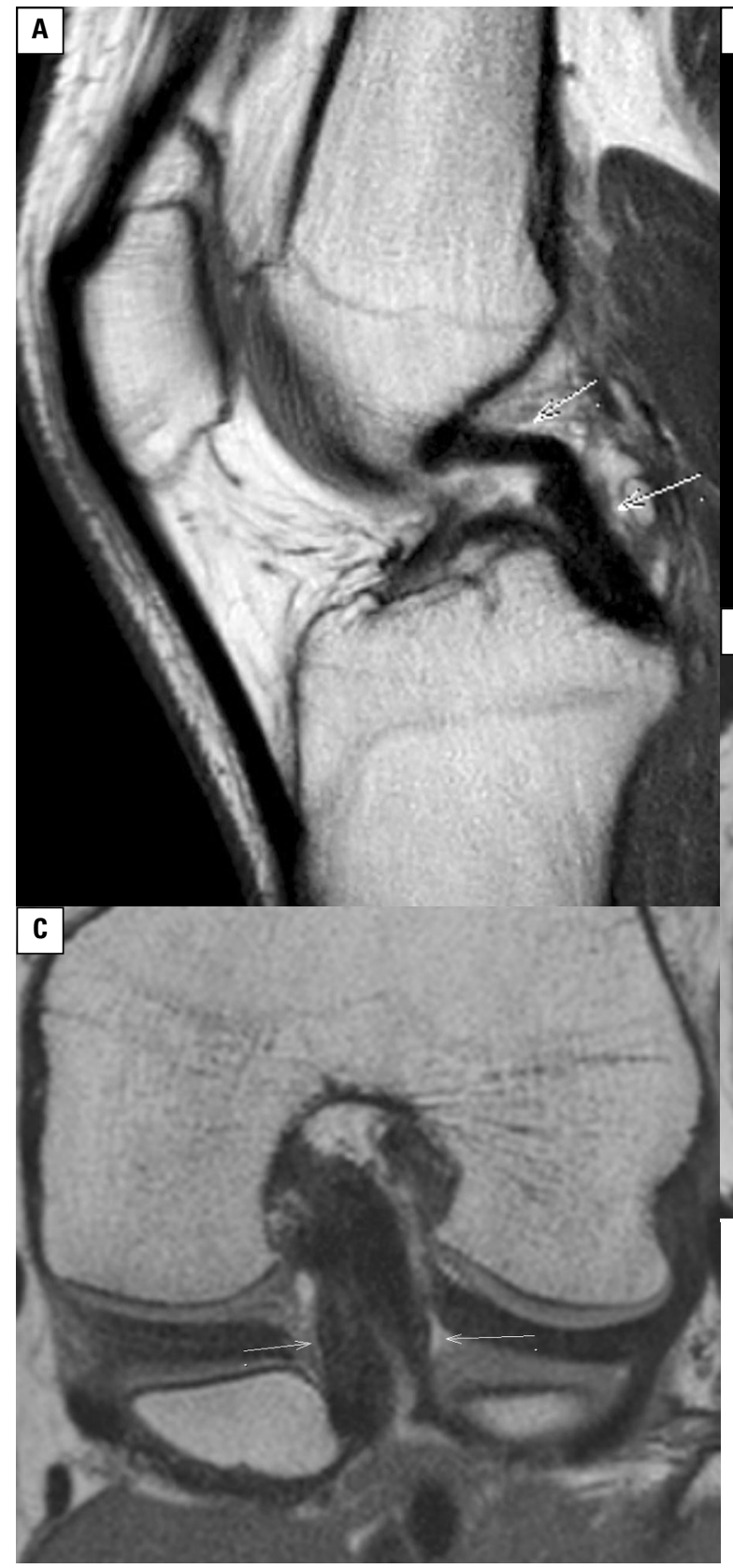

An ACL comprising three separate bundles has been described in several arthroscopic and cadaveric studies where an additional intermediate (IM) bundle has been identified [16, 22, 24].

Anterior cruciate ligament may also be hypoplastic, absent, replaced by a fibrous band or fatty degenerated [13].

Agenesis of $A C L$ is typically associated with other lower limb anomalies such as, among others, retained meniscus, complete congenital absence of menisci, concomitant absence of PCL, shortening of the femur,

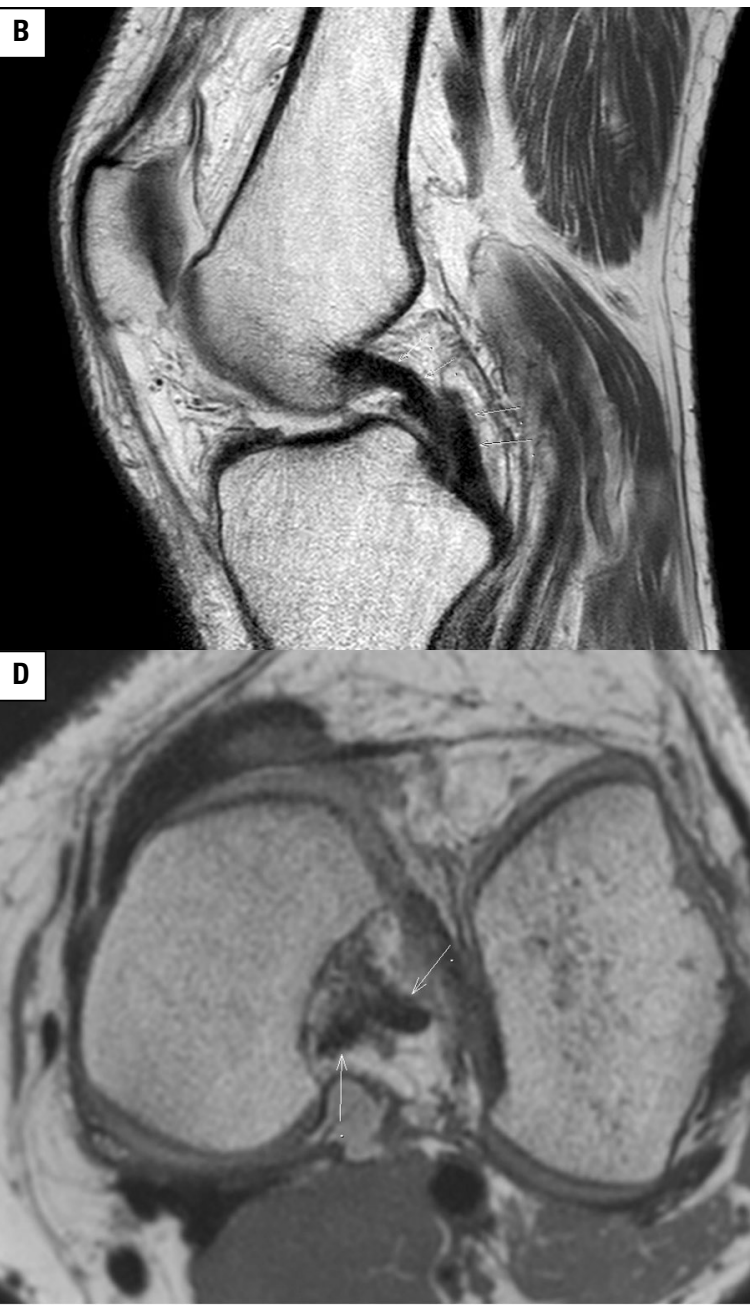

Figure 9. Posterior cruciate ligament (PCL); A. In sagittal plane in proton-density (PD)-weighted turbo spin-echo (TSE) sequence. Arrows indicate the ligament running from the posterolateral part of the medial condyle of the femur to the posterior intercondylar area of the tibia; B. "Double PCL sign", secondarily to a bucket handle tear of the medial meniscus in sagittal plane in PD-weighted TSE sequence. C. A double PCL — PCL visible as two separate bundles in coronal plane in PD-weighted TSE sequence. D. A double PCL — PCL visible as two separate bundles in axial plane in PD-weighted TSE sequence.

fibular hemimelia, Humphrey's ligament hypertrophy, tibial hypoplasia [10].

\section{POSTERIOR CRUCIATE LIGAMENT}

The posterior cruciate ligament (PCL) (Fig. 9) runs from the posterolateral part of the medial condyle of the femur to the posterior intercondylar area of the tibia.

Similar to ACL, PCL also has two bundles: the anterolateral bundle and the posteromedial bundle. Each of them has a different degree of tightness depending 
on the degree of knee flexion [9]. In MRI the ligament has a hypointense signal and is clearly visible in the sagittal section while its attachments are best seen in the frontal and cross sections. In short echo-time sequences $\mathrm{PCL}$ may have intermediate signal intensity. PCL bundles may be visible as two separate structures, thus forming a double PCL [34], which should be differentiated from a "double PCL sign". The double PCL sign consists in the occurrence of a linear hypointense structure parallel to $\mathrm{PCL}$, secondarily to a bucket handle tear of the medial meniscus. A false "double PCL" may also result from the presence of such anatomical structures as menisco-meniscal and menisco-femoral ligaments. Posterior oblique fibres of PCL were identified, which can be misinterpreted as PMFemL if their distal attachments are not properly identified [2].

Deviations from the above-described normal PCL are rare.

On very rare occasions, centrally displaced tears of both menisci can produce a triple PCL sign [14]. These should not be confused with a true double-bundle PCL. This is where the PCL comprises two clearly separate bundles that both take origin from the posterior tibial plateau and insert side-by-side on the medial femoral condyle [33, 34].

Hypoplasia or agenesis of PCL are typically associated with lower extremity length abnormalities [13].

\section{SUMMARY}

Anatomical variations are quite commonly encountered on MRI and may be present in as many as $25 \%$ of all patients. Progressive improvements in spatial resolution in MRI of the knee mean that smaller anatomical details, and therefore, normal anatomical variations, are more frequently identified. These variants provide an extra challenge to accurate interpretation. Sound knowledge of both normal and variation anatomy is required to avoid misdiagnoses and overdiagnoses.

\section{REFERENCES}

1. Amis AA, Bull AMJ, Gupte CM, et al. Biomechanics of the $\mathrm{PCL}$ and related structures: posterolateral, posteromedial and meniscofemoral ligaments. Knee Surg Sports Traumatol Arthrosc. 2003; 11(5): 271-281, doi: 10.1007/s00167003-0410-7, indexed in Pubmed: 12961064.

2. Amis AA, Gupte CM, Bull AMJ, et al. Anatomy of the posterior cruciate ligament and the meniscofemoral ligaments. Knee Surg Sports Traumatol Arthrosc. 2006; 14(3): 257-263, doi: 10.1007/s00167-005-0686-x, indexed in Pubmed: 16228178.
3. Bolog N, Hodler J. MR imaging of the posterolateral corner of the knee. Skeletal Radiol. 2007; 36(8): 715-728, doi: 10.1007/s00256-006-0271-5, indexed in Pubmed: 17334760.

4. Bozkurt M, Elhan A, Tekdemir I, et al. An anatomical study of the meniscofibular ligament. Knee Surg Sports Traumatol Arthrosc. 2004; 12(5): 429-433, doi: 10.1007/ /s00167-003-0450-z, indexed in Pubmed: 14634721.

5. Carpenter WA. Meniscofemoral ligament simulating tear of the lateral meniscus: MR features. J Comput Assist Tomogr. 1990; 14(6): 1033-1034, indexed in Pubmed: 2229555.

6. Chan CM, Goldblatt JP. Unilateral meniscomeniscal ligament. Orthopedics. 2012; 35(12): e1815-e1817, doi: 10.3928/01477447-20121120-31, indexed in Pubmed: 23218643 .

7. Cho JM, Suh JS, Na JB, et al. Variations in meniscofemoral ligaments at anatomical study and MR imaging. Skeletal Radiol. 1999; 28(4): 189-195, indexed in Pubmed: 10384988.

8. Dervin GF, Paterson RS. Oblique menisco-meniscal ligament of the knee. Arthroscopy. 1997; 13(3): 363-365, indexed in Pubmed: 9195035.

9. Edwards A, Bull AMJ, Amis AA. The attachments of the fiber bundles of the posterior cruciate ligament: an anatomic study. Arthroscopy. 2007; 23(3): 284-290, doi: 10.1016/j. arthro.2006.11.005, indexed in Pubmed: 17349472.

10. Ergün $S$, Karahan $M, A k g u ̈ n ~ U$, et al. [A case of multiple congenital anomalies including agenesis of the anterior cruciate ligament]. Acta Orthop Traumatol Turc. 2008; 42(5): 373-376, indexed in Pubmed: 19158459.

11. Gupte CM, Smith A, McDermott ID, et al. Meniscofemoral ligaments revisited. Anatomical study, age correlation and clinical implications. J Bone Joint Surg Br. 2002; 84(6): 846-851, indexed in Pubmed: 12211675.

12. Ishigooka H, Sugihara T, Shimizu K, et al. Anatomical study of the popliteofibular ligament and surrounding structures. J Orthop Sci. 2004; 9(1): 51-58, doi: 10.1007/ s00776-003-0733-8, indexed in Pubmed: 14767705.

13. Kaelin A, Hulin PH, Carlioz H. Congenital aplasia of the cruciate ligaments. A report of six cases. J Bone Joint Surg Br. 1986; 68(5): 827-828, indexed in Pubmed: 3782255.

14. Kakel $R$, Russell $R$, VanHeerden $P$. The triple $P C L$ sign: bucket handle tears of both medial and lateral menisci in a chronically ACL-deficient knee. Orthopedics. 2010; 33(10): 772, doi: 10.3928/01477447-20100826-22, indexed in Pubmed: 20954659.

15. Kaplan EB. The lateral meniscofemoral ligament of the knee joint. Bull Hosp Joint Dis. 1956; 17(2): 176-182, indexed in Pubmed: 13413392.

16. Kato $Y$, Ingham SJM, Maeyama A, et al. Biomechanics of the human triple-bundle anterior cruciate ligament. Arthroscopy. 2012; 28(2): 247-254, doi: 10.1016/j.arthro.2011.07.019, indexed in Pubmed: 22019233.

17. Kim SJ, Kim DW, Min BH. Discoid lateral meniscus associated with anomalous insertion of the medial meniscus. Clin Orthop Relat Res. 1995(315): 234-237, indexed in Pubmed: 7634673.

18. Min BH, Ha HK, Khang SY. Medial discoid meniscus completely coalesced with the anterior cruciate ligament. Arthroscopy. 2001; 17(7): E27, indexed in Pubmed: 11536107. 
19. Minowa T, Murakami G, Kura H, et al. Does the fabella contribute to the reinforcement of the posterolateral corner of the knee by inducing the development of associated ligaments? J Orthop Sci. 2004; 9(1): 59-65, doi: 10.1007/ s00776-003-0739-2, indexed in Pubmed: 14767706.

20. Munshi M, Pretterklieber ML, Kwak S, et al. MR imaging, MR arthrography, and specimen correlation of the posterolateral corner of the knee: an anatomic study. AJR Am J Roentgenol. 2003; 180(4): 1095-1101, doi: 10.2214/ajr.180.4.1801095, indexed in Pubmed: 12646462.

21. Nelson EW, LaPrade RF. The anterior intermeniscal ligament of the knee. An anatomic study. Am J Sports Med. 2000; 28(1): 74-76, doi: 10.1177/03635465000280012401, indexed in Pubmed: 10653547.

22. Norwood LA, Cross MJ. Anterior cruciate ligament: functional anatomy of its bundles in rotatory instabilities. Am J Sports Med. 1979; 7(1): 23-26, doi: 10.1177/0363546 57900700106, indexed in Pubmed: 420384.

23. Obaid H, Gartner L, Haydar AA, et al. The meniscofibular ligament: an MRI study. Eur J Radiol. 2010; 73(1): 159-161, doi: 10.1016/j.ejrad.2008.09.026, indexed in Pubmed: 18995979.

24. Otsubo $H$, Shino $K$, Suzuki $D$, et al. The arrangement and the attachment areas of three ACL bundles. Knee Surg Sports Traumatol Arthrosc. 2012; 20(1): 127-134, doi: 10.1007/s00167-011-1576-z, indexed in Pubmed: 21695467.

25. Pfirrmann CWA, Zanetti M, Hodler J. Joint magnetic resonance imaging: normal variants and pitfalls related to sports injury. Radiol Clin North Am. 2002; 40(2): 167-180, indexed in Pubmed: 12118819.

26. Raheem O, Philpott J, Ryan W, et al. Anatomical variations in the anatomy of the posterolateral corner of the knee. Knee Surg Sports Traumatol Arthrosc. 2007; 15(7): 895-900, doi: 10.1007/s00167-007-0301-4, indexed in Pubmed: 17641923.
27. Recondo JA, Salvador E, Villanúa JA, et al. Lateral stabilizing structures of the knee: functional anatomy and injuries assessed with MR imaging. Radiographics. 2000; $20 \mathrm{Spec}$ No: S91-S9S102, doi: 10.1148/radiographics.20.suppl_1. g00oc02s91, indexed in Pubmed: 11046165.

28. Sanders TG, Linares RC, Lawhorn KW, et al. Oblique meniscomeniscal ligament: another potential pitfall for a meniscal tear--anatomic description and appearance at MR imaging in three cases. Radiology. 1999; 213(1): 213-216, doi: 10.1148/radiology.213.1.r99oc20213, indexed in Pubmed: 10540664.

29. Seebacher JR, Inglis AE, Marshall JL, et al. The structure of the posterolateral aspect of the knee. J Bone Joint Surg Am. 1982; 64(4): 536-541, indexed in Pubmed: 7068696.

30. Sintzoff SA, Stallenberg B, Gillard I, et al. Transverse geniculate ligament of the knee: appearance and frequency on plain radiographs. Br J Radiol. 1992; 65(777): 766-768, doi: 10.1259/0007-1285-65-777-766, indexed in Pubmed: 1393411.

31. Snoeckx A, Vanhoenacker FM, Gielen JL, et al. Magnetic resonance imaging of variants of the knee. Singapore Med J. 2008; 49(9): 734-744, indexed in Pubmed: 18830550.

32. Soejima $T$, Murakami $H$, Tanaka $N$, et al. Anteromedial meniscofemoral ligament. Arthroscopy. 2003; 19(1): 90-95, doi: 10.1053/jars.2003.50026, indexed in Pubmed: 12522408.

33. Tyler P, Datir A, Saifuddin A. Magnetic resonance imaging of anatomical variations in the knee. Part 1: ligamentous and musculotendinous. Skeletal Radiol. 2010; 39(12): 1161-1173, doi: 10.1007/s00256-009-0870-z, indexed in Pubmed: 20155418.

34. Venkatanarasimha $N$, Kamath A, Mukherjee $K$, et al. Potential pitfalls of a double PCL sign. Skeletal Radiol. 2009; 38(8): 735-739, doi: 10.1007/s00256-009-0654-5, indexed in Pubmed: 19234702.

35. Zivanović S. Menisco-meniscal ligaments of the human knee joint. Anat Anz. 1974; 135(1-2): 35-42, indexed in Pubmed: 4479243. 